\title{
Clinical significance of the distance between the cricoid cartilage and upper edge of the tumor using PET-CT in cervical esophageal cancer
}

\author{
KEITA KATSURAHARA, ATSUSHI SHIOZAKI, HITOSHI FUJIWARA, HIROTAKA KONISHI, \\ MICHIHIRO KUDOU, KATSUTOSHI SHODA, TOMOHIRO ARITA, TOSHIYUKI KOSUGA, \\ RYO MORIMURA, YASUTOSHI MURAYAMA, YOSHIAKI KURIU, HISASHI IKOMA, \\ TAKESHI KUBOTA, MASAYOSHI NAKANISHI, KAZUMA OKAMOTO and EIGO OTSUJI
}

\author{
Division of Digestive Surgery, Department of Surgery, University Hospital, \\ Kyoto Prefectural University of Medicine, Kyoto 602-8566, Japan
}

Received April 23, 2020; Accepted June 19, 2020

DOI: $10.3892 / \mathrm{ol} .2020 .11901$

\begin{abstract}
Cervical esophageal squamous cell carcinoma (CESCC) is less common compared with thoracic esophageal cancer, and few studies have investigated the clinicopathological features of CESCC. The present study analyzed 69 patients with CESCC who underwent various therapies at the University Hospital of Kyoto Prefectural University of Medicine between January 2000 and December 2016. The distance between the inferior border of the cricoid cartilage and upper edge of the tumor was evaluated using positron emission tomography and computed tomography. Positive and negative values indicated oral and anal directions, respectively. Using receiver operating characteristic curves, the cut-off value for laryngeal preservation was calculated as $-5 \mathrm{~mm}$. According to this value, the patients were divided into two groups: The short group (distance from the cricoid cartilage $\geq-5 \mathrm{~mm}$ ) and long group (distance from the cricoid cartilage $<-5 \mathrm{~mm}$ ). There were no significant differences in clinicopathological factors between the two groups except for body mass index. In univariate analysis, the 3-year overall survival rate was significantly lower in short group (45.4 vs. $79.6 \% ; \mathrm{P}=0.009)$. In multivariate analysis, short group was an independent prognostic risk factor (hazard ratio $=2.65$; $\mathrm{P}=0.039)$. This may be due to lymphatic flow around the cervical esophagus.
\end{abstract}

Correspondence to: Dr Atsushi Shiozaki, Division of Digestive Surgery, Department of Surgery, University Hospital, Kyoto Prefectural University of Medicine, 465 Kajii-cho, Kamigyo-ku, Kyoto 602-8566, Japan

E-mail: shiozaki@koto.kpu-m.ac.jp

Key words: cervical esophageal cancer, PET-CT, distance from the cricoid cartilage, laryngeal preservation

\section{Introduction}

Esophageal cancer was the eighth most common cancer worldwide, and the sixth most common cause of cancer-associated death in 2012 (1). Adenocarcinoma of the cervical esophagus is uncommon, and squamous cell carcinoma is usually observed (2). Cervical esophageal squamous cell carcinoma (CESCC) has been reported to represent $\sim 5 \%$ of esophageal cancer cases (3-5), and tobacco and alcohol consumption are risk factors for CESCC, the same as for thoracic esophageal cancer $(6,7)$.

Surgical resection or chemoradiotherapy (CRT) are widely accepted as initial treatments, but a standard therapy has not yet been established for patients with CESCC (8-13). CRT is often selected for patients with unresectable tumors or those who are not candidates for surgery based on patient selection and general condition $(9,14)$. Some patients who undergo surgery for CESCC require total pharyngo-laryngectomy, which is associated with speech impairment and compromises a quality of life (12).

The cervical esophagus is defined as the upper part of the esophagus between the cricopharyngeal muscle and the thoracic inlet, and is $\sim 18 \mathrm{~cm}$ from the incisor teeth (15). CESCC is surrounded by various structures, such as the hypopharynx, larynx, trachea and thyroid gland (16-19). The anatomical complexity of the cervical esophagus makes surgery more dangerous (16-19). The surgical procedure for CESCC is subtotal esophagectomy often with pharyngo-laryngectomy, depending on tumor progression and the superior extent of the tumor $(20,21)$. It is well known that laryngeal preservation is more difficult if a tumor extends to the oral side $(20,21)$. Marmuse et al (22) reported that a $2 \mathrm{~cm}$ surgical margin was needed for laryngeal preservation for CESCC. However, few studies have investigated the association between the upward extension of the tumor and laryngeal preservation or prognosis in CESCC.

In previous studies, the 5-year survival rates of CESCC were reported to be $18-35 \%(8,23,24)$. These results are similar to those for thoracic esophageal cancer (3-5). Yamada et al (25) 
reported that performance status and tumor length $>6 \mathrm{~cm}$ were prognostic risk factors for CESCC. However, there are few reports investigating the risk factors for CESCC. Therefore, the aim of the present study was to measure the distance between the inferior border of the cricoid cartilage and upper edge of the tumor using positron emission tomography and computed tomography (PET-CT), and to evaluate the association between this distance and clinicopathological factors.

\section{Materials and methods}

Patients. Between January 2000 and December 2016, 73 patients with CESCC underwent treatments at the University Hospital of Kyoto Prefectural University of Medicine. Of these, four cases were excluded from the study because they were clinically diagnosed with distant metastasis or had a history of esophagectomy. The median age of patients was 66 years (range, 60-72 years), and 53 patients were males and 16 were females. Preoperative age, sex, body mass index (BMI) and American Society of Anesthesiologists' Physical Status (ASA-PS) were recorded (26). The present study was conducted in accordance with the principles of the Declaration of Helsinki, and written informed consent was obtained from all patients. The study was approved by the Research Ethics Committee of the Kyoto Prefectural University of Medicine (approval no. ERB-C-1414-1).

Surgery. A total of 48 out of 69 patients underwent surgery. In 20 patients with invasion of the pharynx or trachea and upper thoracic esophagus, pharyngo-laryngo-total esophagectomy with neck and mediastinal lymph node dissection and reconstruction with a gastric tube was performed. In seven patients with invasion of the pharynx or trachea, pharyngo-laryngo-cervical esophagectomy with neck and upper mediastinal lymph node dissection and reconstruction with free jejunal transfer was performed. Subtotal esophagectomy with neck and mediastinal lymph node dissection and reconstruction with a gastric tube or ileocolonic reconstruction was performed in 20 cases in which it was possible to preserve the larynx and the tumor extended to upper thoracic esophagus. One patient underwent cervical esophagectomy with laryngeal preservation with neck and upper mediastinal lymph node dissection and reconstruction with free jejunal transfer.

The absence of cancer cells in the proximal margin was confirmed pathologically, but if the patients wanted to preserve the larynx, there were some cases where a laryngeal-preserving procedure was later performed with residual cancer and CRT. The definitions of degrees of resection are defined in R0 (complete resection), R1 (incomplete resection, with microscopic residual disease) and R2 (incomplete resection, with gross residual disease). A positive surgical margin was classified as R1/R2 (27).

Distance from the cricoid cartilage to the upper edge of the tumor. Makino et al (28), reported a method to evaluate the upward extension of a tumor. As the cricoid cartilage is at the same height as the esophageal entrance, this method can measure the distance from the esophagus entrance. According to this method, the distance between the inferior border of the cricoid cartilage and upper edge of the tumor was measured using a sagittal PET-CT. At the University Hospital of Kyoto Prefectural University of Medicine, values of standard fluorodeoxyglucose uptake (SUV) were measured by placing volumetric regions of interest over PET/CT images, and SUV $\geq 2.5$ was considered to indicate a malignant lesion. Positive and negative values indicate oral and anal directions, respectively. The distance from the cricoid cartilage was measured using PET-CT when patients were diagnosed with CESCC.

Neoadjuvant chemotherapy (NAC). NAC was administered to patients with cStage II or III, according to the JCOG9907 study (29), which was diagnosed based on the Japanese Classification of Esophageal Cancer (27). Two cycles of standard 5-Fluorouracil (FU) and cisplatin (one cycle was three weeks long, including $800 \mathrm{mg} /$ body/day 5-FU on days $1-5$ as a $24-\mathrm{h}$ continuous infusions plus $80 \mathrm{mg} /$ body/day cisplatin on day 1 as a 1-h drip infusion) were used between 2007 and 2013. Since 2011, two cycles of DCF as NAC for patients with cStageIII and good general condition (based on age, ASA-PS and medical history) were administered. Some patients received two cycles of 5-FU, cisplatin and docetaxel therapy as NAC (one cycle was three weeks long, including $750 \mathrm{mg} /$ body/day 5 -FU on days $1-5$ as a $24-\mathrm{h}$ continuous infusions, plus $70 \mathrm{mg} /$ body/day cisplatin and $70 \mathrm{mg} /$ body/day docetaxel on day 1 as a 1-h drip infusion) (30). These patients underwent upper endoscopy and CT after NAC, and the resectability of their tumors was re-evaluated.

Neoadjuvant chemoradiotherapy (NACRT). NACRT combined with two cycles of low-dose 5-FU and cisplatin therapy (one cycle was one week long, including 250-500 mg body/day 5-FU on days 1-5 as a 24-h continuous infusion plus $10 \mathrm{mg}$ body/day, cisplatin on days $1-5$ as a $1-\mathrm{h}$ drip infusion) with 40 Gy radiotherapy was administered to patients with an invasion depth of clinical T3 or to the adjacent structures (T4) (27) between 2000 and 2007. If a tumor was resectable based on upper-endoscopy and CT scans performed after NACRT, resection surgery was performed.

Definitive chemoradiotherapy ( $d C R T)$. dCRT was administered to clinical T4 cases or patients who refused curative surgery. Low-dose or standard 5-FU and cisplatin therapy were used as combined chemotherapy (31). Salvage surgery after dCRT was performed on recurrent cases after complete response (CR) or non-CR that were resectable. Patients who underwent surgery as the initial treatment were classified as the surgery group and patients who underwent dCRT as the initial treatment were classified as the dCRT group. Patients who underwent NACRT were included in the surgery group, and salvage surgery cases were included in the dCRT group.

Follow-up. Blood tests (using the tumor markers squamous cell carcinoma and carcinoembryonic antigens), gastrointestinal endoscopy and PET-CT scanning of the neck, chest and abdomen were performed approximately every 6 months after the initiation of treatment until death or loss to follow-up. Overall survival times were calculated from the time of diagnosis until either death, loss during follow-up or the end of the 
Table I. Characteristics of 69 patients with cervical esophageal squamous cell carcinoma at initial treatment.

\begin{tabular}{|c|c|c|c|c|}
\hline Variable & Total, n & Surgery, $\mathrm{n}$ & $\mathrm{dCRT}, \mathrm{n}$ & P-value \\
\hline Age, years & & & & 0.145 \\
\hline$\geq 65$ & 40 & 25 & 15 & \\
\hline$<65$ & 29 & 13 & 16 & \\
\hline Sex & & & & 0.574 \\
\hline Male & 53 & 28 & 25 & \\
\hline Female & 16 & 10 & 6 & \\
\hline BMI & & & & 0.458 \\
\hline$\geq 20$ & 30 & 15 & 15 & \\
\hline$<20$ & 39 & 23 & 16 & \\
\hline ASA-PS & & & & 0.757 \\
\hline $1 / 2$ & 57 & 32 & 25 & \\
\hline $3 / 4$ & 12 & 6 & 6 & \\
\hline $\mathrm{cT}$ & & & & 0.168 \\
\hline $\mathrm{T} 1$ & 9 & 6 & 3 & \\
\hline $\mathrm{T} 2 / \mathrm{T} 3$ & 35 & 22 & 13 & \\
\hline $\mathrm{T} 4$ & 25 & 10 & 15 & \\
\hline Tumor length, mm & & & & 0.726 \\
\hline$\geq 40$ & 35 & 20 & 15 & \\
\hline$<40$ & 34 & 18 & 16 & \\
\hline $\mathrm{cN}$ & & & & 0.589 \\
\hline No & 20 & 10 & 10 & \\
\hline N1-N3 & 49 & 28 & 21 & \\
\hline cStage & & & & 0.468 \\
\hline $0 / \mathrm{I}$ & 7 & 4 & 3 & \\
\hline II/III & 43 & 26 & 17 & \\
\hline IV & 19 & 8 & 11 & \\
\hline
\end{tabular}

BMI, body mass index; ASA-PS, American Society of Anesthesiologists' Physical Status; cT, clinical T; $\mathrm{cN}$, clinical N; dCRT, definitive chemoradiotherapy.

study. Follow-up was performed in the clinic and the average length of follow-up was 3.03 years.

Statistical analysis. Data in our computerized database were examined in the present retrospective study. Additional data were obtained by reviewing medical records. All analyses were performed using JMP software version 12 (SAS Institute Inc.). Comparisons between categorical variables were performed between groups using a $\chi^{2}$ or Fisher's exact test. Mann-Whitney $\mathrm{U}$ test was used for comparisons between continuous variables. The diagnostic accuracy was determined based on the area under the receiver operating characteristic (ROC) curve. The optimal cut-off value for laryngeal preservation was defined as $-5 \mathrm{~mm}$ using Youden's index. The patients were divided into two groups according to the presence or absence of laryngeal preservation, and their clinicopathological features were compared. In survival analysis, comparisons between two groups were analyzed using the log-rank test. Multivariate analysis was performed using Cox's proportional hazards
Table II. Comparison between the two groups according to laryngeal preservation in surgery cases $(n=48)$.

\begin{tabular}{|c|c|c|c|c|}
\hline \multirow[b]{2}{*}{ Variable } & \multirow[b]{2}{*}{ Total, n } & \multicolumn{2}{|c|}{$\begin{array}{c}\text { Laryngeal } \\
\text { preservation, } \mathrm{n}\end{array}$} & \multirow[b]{2}{*}{ P-value } \\
\hline & & - & + & \\
\hline Age, years & & & & $>0.999$ \\
\hline$\geq 65$ & 28 & 16 & 12 & \\
\hline$<65$ & 20 & 11 & 9 & \\
\hline Sex & & & & 0.185 \\
\hline Male & 36 & 18 & 18 & \\
\hline Female & 12 & 9 & 3 & \\
\hline BMI & & & & $0.008^{\mathrm{a}}$ \\
\hline$\geq 20$ & 21 & 7 & 14 & \\
\hline$<20$ & 27 & 20 & 7 & \\
\hline ASA-PS & & & & $>0.999$ \\
\hline $1 / 2$ & 41 & 23 & 18 & \\
\hline $3 / 4$ & 7 & 4 & 3 & \\
\hline $\mathrm{cT}$ & & & & 0.090 \\
\hline $\mathrm{T} 1$ & 6 & 3 & 3 & \\
\hline T2/T3 & 27 & 12 & 15 & \\
\hline $\mathrm{T} 4$ & 15 & 12 & 3 & \\
\hline Tumor length, mm & & & & 0.776 \\
\hline$\geq 40$ & 22 & 13 & 9 & \\
\hline$<40$ & 26 & 14 & 12 & \\
\hline $\mathrm{cN}$ & & & & 0.214 \\
\hline N0 & 14 & 10 & 4 & \\
\hline N1-N3 & 34 & 17 & 17 & \\
\hline cStage & & & & 0.512 \\
\hline I & 4 & 2 & 2 & \\
\hline II/III & 33 & 17 & 16 & \\
\hline IV & 11 & 8 & 3 & \\
\hline NAT & & & & 0.338 \\
\hline Present & 35 & 18 & 17 & \\
\hline Absent & 13 & 9 & 4 & \\
\hline NAT effect & & & & 0.602 \\
\hline CR & 1 & 1 & 0 & \\
\hline PR & 12 & 5 & 7 & \\
\hline SD & 22 & 12 & 10 & \\
\hline
\end{tabular}

${ }^{a} \mathrm{P}<0.01$. BMI, body mass index; ASA-PS, American Society of Anesthesiologists' Physical Status; cT, clinical T; cN, clinical N; cStage, clinical stage; NAT, neoadjuvant therapy; CR, complete response; $\mathrm{PR}$, partial response; $\mathrm{SD}$, stable disease.

model. $\mathrm{P}<0.05$ was considered to indicate a statistically significant difference.

\section{Results}

Patient characteristics. Table I shows the clinicopathological features of the two groups according to initial treatment. There were more patients who were clinical T4 in the dCRT group 


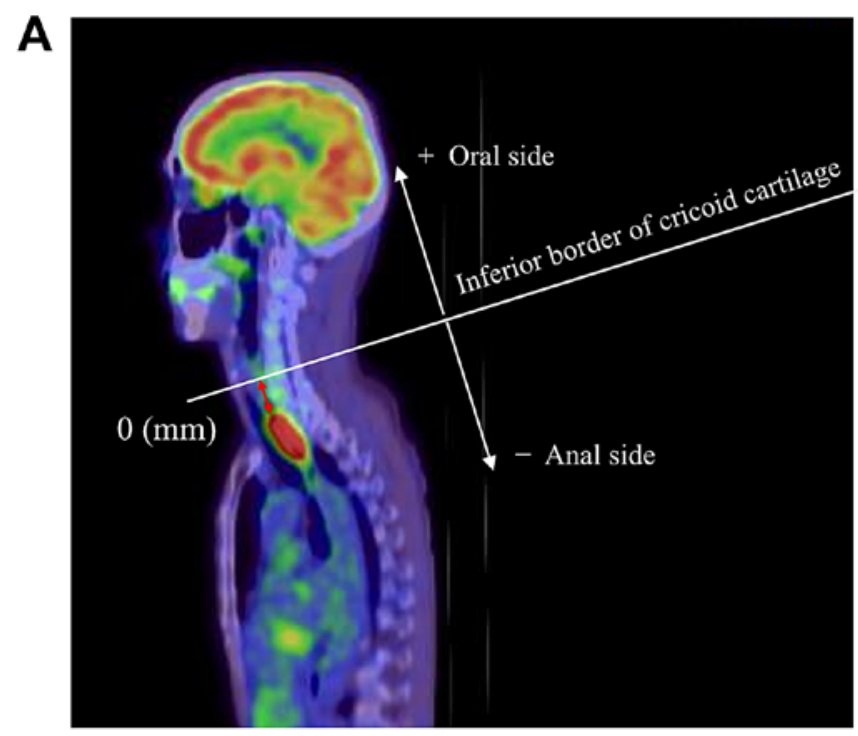

B

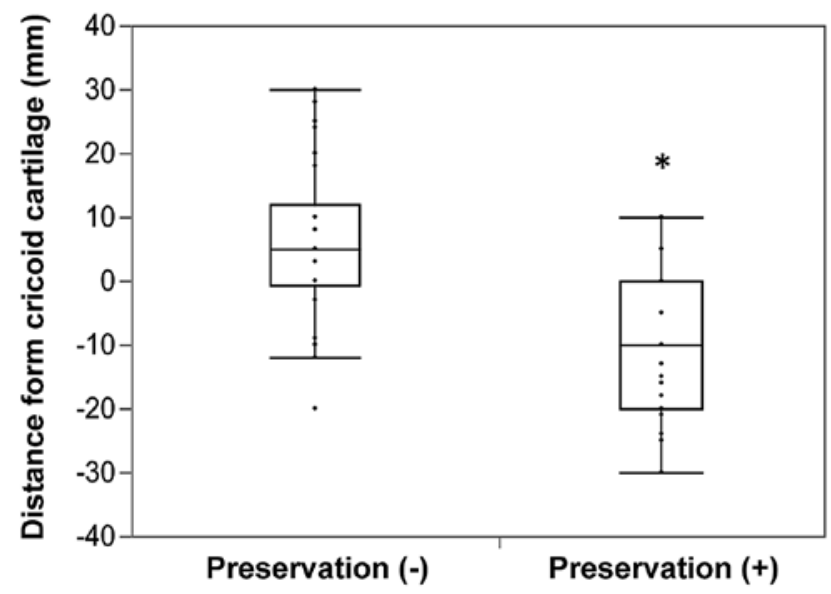

C

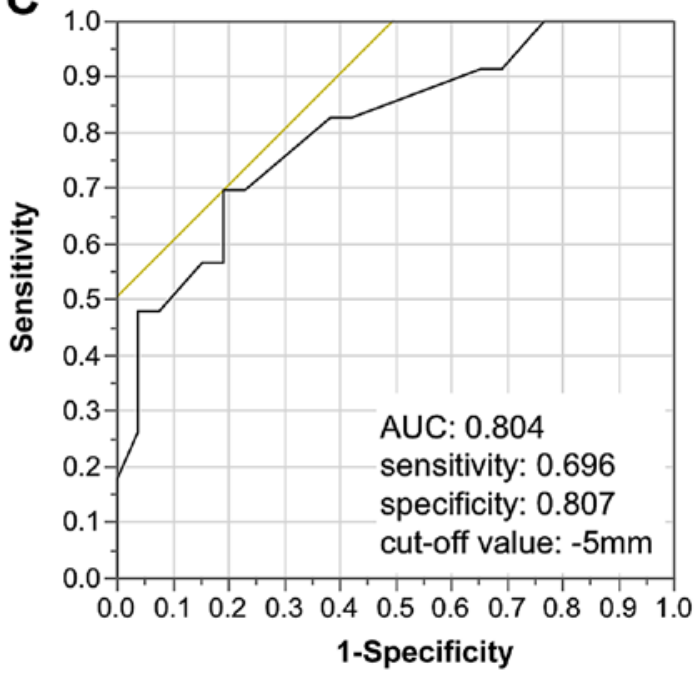

Figure 1. Distance between the inferior border of the cricoid cartilage and upper tumor edge. (A) Distance from the cricoid cartilage was measured using sagittal positron emission tomography computed tomography. Positive and negative values indicate oral and anal directions, respectively. The red arrow indicates actual measurement points. (B) Comparison of the distance from the cricoid cartilage between the non-laryngeal preservation and preservation groups for patients who underwent surgery $(\mathrm{n}=48)$. Box plots have whiskers with a maximum 1.5 times the interquartile range, and the boxes represent first, second (median) and third quartiles. Data were analyzed using a Mann-Whitney U test. (C) Cut-off value for laryngeal preservation in patients who underwent surgery was calculated using the receiver operating characteristic curve $(n=48)$. ${ }^{*} \mathrm{P}<0.05$. AUC, area under the curve.

compared with in the surgery group. No significant differences were observed in terms of age, sex, BMI, ASA-PS or clinical N and stage between the two groups.

Distance from the cricoid cartilage. The association between laryngeal preservation and tumor extension was investigated. The distance between the inferior border of the cricoid cartilage and upper edge of the tumor was measured, as evaluated using sagittal PET-CT (Fig. 1A). No significant difference was observed in distance from the cricoid cartilage in the surgery group compared with the dCRT group as initial treatment (mean distance, $-0.32 \pm 14.14$ vs. $-6.00 \pm 14.890 \mathrm{~mm} ; \mathrm{P}=0.181$; data not shown).

Esophagectomy was performed on 48 patients, and of these, laryngeal-preserving procedures were performed on 21 patients. The patients were divided into two groups according to the presence or absence of laryngeal preservation and their clinicopathological features were compared. Table II shows that there was a significant association between BMI and laryngeal preservation $(\mathrm{P}=0.008)$, while no significant differences were observed in terms of age, sex, ASA-PS, tumor length, neoadjuvant therapy (NAT), NAT effect or clinical T, N and stage between the two groups. Clinicopathological factors between patients with $\mathrm{BMI} \geq 20$ and $<20$ were compared. Table SI shows that BMI was significantly associated with tumor length, the distance from the cricoid cartilage and laryngeal preservation ( $\mathrm{P}=0.032, \mathrm{P}=0.018$ and $\mathrm{P}=0.008$, respectively), while $\mathrm{BMI}$ was not associated with clinical T or NAT.

The distances from the cricoid cartilage with and without laryngeal preservation were compared. Fig. 1B shows that tumors extended more to the upper side in the non-preservation group compared with the preservation group (mean distance, $5.44 \pm 12.54$ vs. $-10.81 \pm 11.37 \mathrm{~mm}$; $\mathrm{P}<0.05$ ). Using the ROC curve, the cut-off value for laryngeal preservation 
Table III. Comparison between the two groups according to distance between the cricoid cartilage and upper tumor edge $(n=69)$.

\begin{tabular}{|c|c|c|c|c|}
\hline \multirow[b]{2}{*}{ Variable } & \multirow[b]{2}{*}{ Total, n } & \multicolumn{2}{|c|}{$\begin{array}{l}\text { Distance } \\
\text { group, } \mathrm{n}\end{array}$} & \multirow[b]{2}{*}{ P-value } \\
\hline & & Short & Long & \\
\hline Age, years & & & & 0.908 \\
\hline$\geq 65$ & 40 & 24 & 16 & \\
\hline$<65$ & 29 & 17 & 12 & \\
\hline Sex & & & & 0.562 \\
\hline Male & 53 & 30 & 23 & \\
\hline Female & 16 & 11 & 5 & \\
\hline BMI & & & & $0.017^{\mathrm{a}}$ \\
\hline$\geq 20$ & 30 & 13 & 17 & \\
\hline$<20$ & 39 & 28 & 11 & \\
\hline ASA-PS & & & & $>0.999$ \\
\hline $1 / 2$ & 57 & 34 & 23 & \\
\hline $3 / 4$ & 12 & 7 & 5 & \\
\hline $\mathrm{cT}$ & & & & 0.949 \\
\hline 1 & 9 & 5 & 4 & \\
\hline $2 / 3$ & 35 & 17 & 18 & \\
\hline 4 & 25 & 19 & 6 & \\
\hline Tumor length, mm & & & & $0.038^{\mathrm{a}}$ \\
\hline$\geq 40$ & 35 & 25 & 10 & \\
\hline$<40$ & 34 & 16 & 18 & \\
\hline $\mathrm{cN}$ & & & & 0.111 \\
\hline 0 & 20 & 15 & 5 & \\
\hline $1-3$ & 49 & 26 & 23 & \\
\hline cStage & & & & 0.282 \\
\hline $0 / \mathrm{I}$ & 7 & 3 & 4 & \\
\hline II/III & 43 & 24 & 19 & \\
\hline IV & 19 & 14 & 5 & \\
\hline Laryngeal preservation & & & & $0.002^{\mathrm{a}}$ \\
\hline Present & 42 & 19 & 23 & \\
\hline Absent & 27 & 22 & 5 & \\
\hline $\begin{array}{l}{ }^{a} \mathrm{P}<0.05 \text {. BMI, body mass } \\
\text { Anesthesiologists' Physical } \\
\text { cStage: Clinical Stage; Dis } \\
\text { lage and upper tumor edge; } \\
\geq-5 \mathrm{~mm} \text {; Long, distance fro }\end{array}$ & $\begin{array}{l}\text { index; AS } \\
\text { Status; cT } \\
\text { ance, distal } \\
\text { Short, dista } \\
\mathrm{m} \text { the cricol }\end{array}$ & $\begin{array}{l}\text { A-PS, Al } \\
\text { clinical } \\
\text { ce betwe } \\
\text { ce from } \\
\text { cartilag }\end{array}$ & $\begin{array}{l}\text { herican } \\
\text { T; } \mathrm{cN} \text { : } \\
\text { n the cri } \\
\text { he cricoi } \\
<-5 \mathrm{~mm}\end{array}$ & $\begin{array}{l}\text { Society of } \\
\text { Clinical N, } \\
\text { coid carti- } \\
\text { d cartilage } \\
\end{array}$ \\
\hline
\end{tabular}

was calculated as $-5 \mathrm{~mm}(\mathrm{AUC}=0.804$, sensitivity $=0.696$, specificity $=0.807$, Youden's index; Fig. 1C). According to the cut-off value, the patients were divided into two groups: The short group (distance from the cricoid cartilage $\geq-5 \mathrm{~mm}$ ) and long group (distance from the cricoid cartilage $<-5 \mathrm{~mm}$ ). The clinicopathological features of the two groups are presented in Table III, which shows that the distance from the cricoid cartilage was significantly associated with laryngeal preservation, $\mathrm{BMI}$ and tumor length $(\mathrm{P}=0.002, \mathrm{P}=0.017$ and $\mathrm{P}=0.038$, respectively).
Table IV. Three-year overall survival rates of patients with cervical esophageal squamous cell carcinoma.

\begin{tabular}{|c|c|c|c|}
\hline Variable & $\begin{array}{c}\text { Total } \\
(n=69)\end{array}$ & $\begin{array}{c}\text { 3-year } \\
\text { OS rate, \% }\end{array}$ & $\begin{array}{c}\text { Univariate analysis } \\
\text { P-value }\end{array}$ \\
\hline Age, years & & & 0.988 \\
\hline$\geq 65$ & 40 & 60.6 & \\
\hline$<65$ & 29 & 58.7 & \\
\hline Sex & & & 0.539 \\
\hline Male & 53 & 55.7 & \\
\hline Female & 16 & 74.5 & \\
\hline BMI & & & 0.747 \\
\hline$\geq 20$ & 30 & 60.6 & \\
\hline$<20$ & 39 & 59.3 & \\
\hline ASA-PS & & & 0.237 \\
\hline $1 / 2$ & 57 & 62.9 & \\
\hline $3 / 4$ & 12 & 45.5 & \\
\hline $\mathrm{cT}$ & & & $<0.0001^{\mathrm{a}}$ \\
\hline $1-3$ & 44 & 75.7 & \\
\hline 4 & 25 & 29.2 & \\
\hline Tumor length, mm & & & 0.152 \\
\hline$\geq 40$ & 35 & 54.7 & \\
\hline$<40$ & 34 & 64.0 & \\
\hline $\mathrm{cN}$ & & & 0.932 \\
\hline 0 & 20 & 63.3 & \\
\hline $1-3$ & 49 & 58.2 & \\
\hline Distance group & & & $0.009^{\mathrm{b}}$ \\
\hline Short & 41 & 45.4 & \\
\hline Long & 28 & 79.6 & \\
\hline Initial treatment & & & 0.360 \\
\hline $\mathrm{dCRT}$ & 31 & 54.0 & \\
\hline Operation & 38 & 63.9 & \\
\hline
\end{tabular}

${ }^{\mathrm{a}} \mathrm{P}<0.0001,{ }^{\mathrm{b}} \mathrm{P} \leq 0.001$. OS, overall survival rate; BMI, body mass index; ASA-PS, American Society of Anesthesiologists' Physical Status; cT, clinical T; cN, clinical N; Distance, distance between the cricoid cartilage and upper tumor edge; Short, patients with distance from the cricoid cartilage $\geq-5 \mathrm{~mm}$; Long, patients with distance from the cricoid cartilage $<-5 \mathrm{~mm}$; dCRT, definitive chemoradiotherapy.

The patterns of recurrence between the absence and presence of laryngeal preservation (Table SII), and between the short and long groups were compared (Table SIII). No significant differences were observed in total recurrence between the groups, but there were significantly more distant metastases and less local recurrence in the non-preservation group than in the preservation group $(\mathrm{P}=0.031$ and 0.029 , respectively; Table SII).

Survival analysis. The 3-year overall survival rates were compared with each clinicopathological factor. In univariate analysis, 3-year overall survival was significantly less favorable in short group (45.4 vs. $79.6 \%$; $\mathrm{P}=0.009)$ and clinical T4 $(29.2$ vs. $75.7 \%, \mathrm{P}<0.0001$; Table IV). In multivariate analysis, short 
Table V. Independent prognostic factors for cervical esophageal squamous cell carcinoma.

\begin{tabular}{lcccc}
\hline & & & \multicolumn{2}{c}{ Multivariate analysis } \\
\cline { 4 - 5 } Variable & Total (n=69) & 3-year OS rate, $\%$ & HR & 95\% CI \\
\hline cT & & & 4.22 & $1.84-10.27$ \\
$1-3$ & 44 & 75.7 & & $0.001^{\mathrm{a}}$ \\
4 & 25 & 29.2 & 2.65 & $0.039^{\mathrm{b}}$ \\
Distance group & & & & $1.04-8.09$ \\
Short & 41 & 45.4 & & \\
Long & 28 & 79.6 & & \\
\hline
\end{tabular}

${ }^{\mathrm{a}} \mathrm{P} \leq 0.001,{ }^{\mathrm{b}} \mathrm{P}<0.05$. OS, overall survival; cT, clinical T; Distance, distance between the cricoid cartilage and upper tumor edge; Short, patients with distance from the cricoid cartilage $\geq-5 \mathrm{~mm}$; Long, patients with distance from the cricoid cartilage $<-5 \mathrm{~mm}$; HR, hazard ratio; CI, confidence interval.

distance and clinical T4 were independent prognostic risk factors for patients with CESCC [hazard ratio $(\mathrm{HR})=2.65 ; 95 \% \mathrm{CI}$, 1.04-8.09; $\mathrm{P}=0.039$ and $\mathrm{HR}=4.22 ; 95 \% \mathrm{CI}, 1.84-10.27 ; \mathrm{P}=0.001$, respectively; Table V). A total of 48 patients who underwent surgery were also analyzed (Table SIV). As a result, short distance and clinical T4 were independent prognostic risk factors in multivariate analysis ( $\mathrm{P}=0.013$ and $\mathrm{P}=0.011$, respectively).

\section{Discussion}

The cervical esophagus is surrounded by various structures, such as the hypopharynx, larynx, trachea and thyroid gland. Patients with CESCC frequently need to undergo pharyngo-laryngo-esophagectomy and quality of life can be greatly impaired (8). The present study investigated which patients with CESCC needed pharyngo-laryngo-esophagectomy and evaluated the distance between the larynx and tumor. As a result, distance from the cricoid cartilage $\geq-5 \mathrm{~mm}$ was found to be an independent prognostic risk factor. To the best of our knowledge, the present study is the first to show that distance from the cricoid cartilage is associated with prognosis. Doyle et al (26) reported that patients with CESCC who underwent laryngeal-preserving surgery had an improved prognosis. In the present study, the 3-year overall survival rate was improved in the laryngeal preservation group compared with the non-preservation group in 48 patients with CESCC who underwent surgery (73.0 vs. $51.8 \%, \mathrm{P}=0.120$; Fig. S1). Patients who underwent laryngeal preservation surgery tended to have an improved prognosis, but this was associated with tumor size, depth, location and length. Of these factors, it was hypothesized that tumor location was associated with prognosis, as distance from the cricoid cartilage $\geq-5 \mathrm{~mm}$ was an independent prognostic risk factor in multivariate analysis (Table SIV).

Table SII showed that there were more patients with distant metastasis in the non-preservation group than in the preservation group, and in the short group than in the long group. Liu et al (32) reported that the incidence of distant metastasis was $7.3 \%$ in hypopharynx cancer, which is relatively high among head and neck cancers. In addition, some studies have reported that positive $\mathrm{N}$-stage is a predictor of distant metastasis in head and neck cancers $(33,34)$. The reason for these results may be that distant metastasis tends to occur from the lymphatic flow around the pharynx. The aforementioned results are consistent with the present data, which revealed that non-preserving larynx cases had numerous distant metastases.

It was hypothesized that the worse prognosis for tumors that extended to the oral side was due to a positive surgical margin, and 48 patients who underwent surgery were analyzed (Table SIII). As a result, pathological R0 or R1/R2 and laryngeal preservation had no significant association with prognosis, while short group was an independent prognostic risk factor. These results suggested that the worse prognosis in short group was not due to a positive surgical margin.

Table II shows that there was a significant association between BMI and laryngeal preservation in surgical cases. Additionally, Table SI revealed that BMI was significantly associated with the distance from the cricoid cartilage and laryngeal preservation, while BMI was not associated with clinical T or NAT. Therefore, it was considered that patients whose tumor had spread to the oral side had a lower BMI due to poor oral intake; however, BMI was not associated with prognosis.

Previous studies investigating esophageal cancer have been based on thoracic esophageal cancer data, and few reports have compared prognosis following surgery and dCRT in patients with CESCC. Takebayashi et al (9) demonstrated that surgery as the initial treatment for CESCC tended to be improved compared with dCRT (5-year overall survival rate, 60.6 vs. $51.4 \%$ ). On the other hand, Valmasoni et al (8) reported that surgery tended to be worse compared with dCRT (5-year overall survival rate, 12.6 vs. 26.7\%). Therefore, the strategy for CESCC treatment is controversial, and it is usually treated based on the strategy for thoracic esophageal cancer. In the present study, surgery as the initial treatment, which included NAC, NACRT and surgery alone, tended to result in an improved prognosis compared with dCRT (3-year overall survival rate, 63.9 vs. $54.0 \%, \mathrm{P}=0.360$; Fig. S2). In addition, salvage surgery when dCRT was non-CR or recurred after $\mathrm{CR}$ had an improved prognosis than without salvage surgery (Fig. S3). These results suggested that CESCC should be treated in the same way as thoracic esophageal cancer. 
The present study has some limitations. There may be some bias because it was a retrospective study and the sample size was not large enough to identify potential differences between the two groups. Another limitation was that patients received different treatments, for example surgery as the initial treatment group included patients who underwent NAC, NACRT and surgery alone. The results of the present study need to be validated in prospective studies with larger sample sizes, and further analysis of tumor status, such as tumor size, tracheal invasion and effects of NAC or CRT are needed.

In summary, the distance between the inferior border of the cricoid cartilage and upper tumor edge $\geq-5 \mathrm{~mm}$ was an independent prognostic factor for CESCC. This may be due to lymphatic flow around the cervical esophagus.

\section{Acknowledgements}

Not applicable.

\section{Funding}

No funding was received.

\section{Availability of data}

The datasets used and/or analyzed during the present study are available from the corresponding author upon reasonable request.

\section{Authors' contributions}

$\mathrm{KK}, \mathrm{AS}$ and EO designed the present study. AS, HF, HK, MK, KS, TA, TKo, RM, YM, YK, HI, TKu, MN, KO and EO performed the surgeries. KK, AS and HF analyzed the data. KK and AS wrote the manuscript. All authors read and approved the final manuscript.

\section{Ethics approval and consent to participate}

All procedures performed in studies involving human participants were in accordance with the ethical standards of the institutional and national research committee and with the 1964 Helsinki declaration and its later amendments or comparable ethical standards. Informed consent was provided by all patients.

\section{Patient consent for publication}

Not applicable.

\section{Competing interests}

The authors declare that they have no competing interests.

\section{References}

1. Ferlay J, Soerjomataram I, Dikshit R, Eser S, Mathers C, Rebelo M, Parkin DM, Forman D and Bray F: Cancer incidence and mortality worldwide: Sources, methods and major patterns in GLOBOCAN 2012. Int J Cancer 136: E359-E386, 2015.
2. Davies L and Welch HG: Epidemiology of head and neck cancer in the United States. Otolaryngol Head Neck Surg 135: 451-457, 2006.

3. Tachimori Y, Ozawa S, Numasaki H, Fujishiro M, Matsubara H, Oyama T, Shinoda M, Toh Y, Udagawa H and Uno T; Registration Committee for Esophageal Cancer of the Japan Esophageal Society: Comprehensive registry of esophageal cancer in Japan, 2009. Esophagus 13: 110-137, 2016.

4. Tachimori Y, Ozawa S, Numasaki H, Ishihara R, Matsubara H, Muro K, Oyama T, Toh Y, Udagawa H and Uno T; Registration Committee for Esophageal Cancer of the Japan Esophageal Society: Comprehensive registry of esophageal cancer in Japan, 2010. Esophagus 14: 189-214, 2017.

5. Tachimori Y, Ozawa S, Numasaki H, Ishihara R, Matsubara H, Muro K, Oyama T, Toh Y, Udagawa H and Uno T; Registration Committee for Esophageal Cancer of the Japan Esophageal Society: Comprehensive registry of esophageal cancer in Japan, 2011. Esophagus 15: 127-152, 2018.

6. Popescu B, Popescu CR, Grigore R, Mogoanta CA, Ionita E, Moculescu C and Bertesteanu SV: Morphology and morphopathology of hypopharyngo-esophageal cancer. Rom J Morphol Embryol 53: 243-248, 2012.

7. Popescu CR, Bertesteanu SV, Mirea D, Grigore R, lonescu D and Popescu B: The epidemiology of hypopharynx and cervical esophagus cancer. J Med Life 3: 396-401, 2010.

8. Valmasoni M, Pierobon ES, Zanchettin G, Briscolini D Moletta L, Ruol A, Salvador R and Merigliano S: Cervical esophageal cancer treatment strategies: A cohort study appraising the debated role of surgery. Ann Surg Oncol 25: 2747-2755, 2018.

9. Takebayashi K, Tsubosa Y, Matsuda S, Kawamorita K, Niihara M, Tsushima T, Yokota T, Sato H, Onozawa Y, Ogawa H, et al: Comparison of curative surgery and definitive chemoradiotherapy as initial treatment for patients with cervical esophageal cancer. Dis Esophagus 30: 1-5, 2017.

10. Hoeben A, Polak J, Van De Voorde L, Hoebers F, Grabsch HI and de Vos-Geelen J: Cervical esophageal cancer: A gap in cancer knowledge. Ann Oncol 27: 1664-1674, 2016.

11. Tong DK, Law S, Kwong DL, Wei WI, Ng RW and Wong KH: Current management of cervical esophageal cancer. World J Surg 35: 600-607, 2011.

12. Chou SH, Li HP, Lee JY, Huang MF, Lee CH and Lee KW: Radical resection or chemoradiotherapy for cervical esophageal cancer? World J Surg 34: 1832-1839, 2010.

13. Adelstein DJ, Rice TW, Tefft M, Koka A, Van Kirk MA, Kirby TJ and Taylor ME: Aggressive concurrent chemoradiotherapy and surgical resection for proximal esophageal squamous cell carcinoma. Cancer 74: 1680-1685, 1994.

14. Gkika E, Gauler T, Eberhardt W, Stahl M, Stuschke M and Pöttgen C: Long-term results of definitive radiochemotherapy in locally advanced cancers of the cervical esophagus. Dis Esophagus 27: 678-684, 2014.

15. Hermans R: Imaging of hypopharyngeal and cervical oesophageal cancer. Cancer Imaging 4: 7-9, 2003.

16. Ott K, Lordick F, Molls M, Bartels H, Biemer E and Siewert JR: Limited resection and free jejunal graft interposition for squamous cell carcinoma of the cervical oesophagus. $\mathrm{Br}$ J Surg 96: 258-266, 2009.

17. Ferahkose Z, Bedirli A, Kerem M, Azili C, Sozuer EM and Akin M: Comparison of free jejunal graft with gastric pull-up reconstruction after resection of hypopharyngeal and cervical esophageal carcinoma. Dis Esophagus 21: 340-345, 2008.

18. Daiko H, Hayashi R, Saikawa M, Sakuraba M, Yamazaki M, Miyazaki M, Ugumori T, Asai M, Oyama W and Ebihara S: Surgical management of carcinoma of the cervical esophagus. J Surg Oncol 96: 166-172, 2007.

19. Kelley DJ, Wolf R, Shaha AR, Spiro RH, Bains MS, Kraus DH and Shah JP: Impact of clinicopathologic parameters on patient survival in carcinoma of the cervical esophagus. Am J Surg 170: 427-431, 1995.

20. Haguenauer JP and Pignat JC: Total pharyngo-laryngo-esophagectomy and reconstruction by gastric or colic pull up. Auris Nasus Larynx 12 (Suppl 2): S41-S43, 1985.

21. Condon HA: Anaesthesia for pharyngo-laryngo-oesophagectomy with pharyngo-gastrostomy. Br J Anaesth 43: 1061-1065, 1971.

22. Marmuse JP, Koka VN, Guedon C and Benhamou G: Surgical treatment of carcinoma of the proximal esophagus. Am J Surg 169: 386-390, 1995.

23. Zhao L, Zhou Y, Mu Y, Chai G, Xiao F, Tan L, Lin SH and Shi M: Patterns of failure and clinical outcomes of definitive radiotherapy for cervical esophageal cancer. Oncotarget 8: 21852-21860, 2017. 
24. Grass GD, Cooper SL, Armeson K, Garrett-Mayer E and Sharma A: Cervical esophageal cancer: A population-based study. Head Neck 37: 808-814, 2015.

25. Yamada K, Murakami M, Okamoto Y, Okuno Y, Nakajima T, Kusumi F, Takakuwa H and Matsusue S: Treatment results of radiotherapy for carcinoma of the cervical esophagus. Acta Oncol 45: 1120-1125, 2006.

26. Doyle DJ, Goyal A, Bansal P and Garmon EH: American Society of Anesthesiologists Classification (ASA Class): In: StatPearls. Treasure Island (FL): StatPearls Publishing, 2020.

27. Japan Esophageal Society: Japanese classification of esophageal cancer, 11th edition: Part II and III. Esophagus 14: 37-65, 2017.

28. Makino T, Yamasaki M, Miyazaki Y, Takahashi T, Kurokawa Y Nakajima K, Takiguchi S, Mori M and Doki Y: Short- and long-term outcomes of larynx-preserving surgery for cervical esophageal cancer: Analysis of 100 consecutive cases. Ann Surg Oncol (Suppl 5) 23: S858-S865, 2016.

29. Ando N, Kato H, Igaki H, Shinoda M, Ozawa S, Shimizu H, Nakamura T, Yabusaki H, Aoyama N, Kurita A, et al: A randomized trial comparing postoperative adjuvant chemotherapy with cisplatin and 5-fluorouracil versus preoperative chemotherapy for localized advanced squamous cell carcinoma of the thoracic esophagus (JCOG9907). Ann Surg Oncol 19: 68-74, 2012.

30. Hara H, Tahara M, Daiko H, Kato K, Igaki H, Kadowaki S Tanaka Y, Hamamoto Y, Matsushita H, Nagase M and Hosoya Y: Phase II feasibility study of preoperative chemotherapy with docetaxel, cisplatin, and fluorouracil for esophageal squamous cell carcinoma. Cancer Sci 104: 1455-1460, 2013.
31. Sai H, Mitsumori M, Yamauchi C, Araki N, Okumura S, Nagata Y, Nishimura Y and Hiraoka M: Concurrent chemoradiotherapy for esophageal cancer: Comparison between intermittent standard-dose cisplatin with 5-fluorouracil and daily low-dose cisplatin with continuous infusion of 5-fluorouracil. Int J Clin Oncol 9: 149-153, 2004.

32. Liu JC, Bhayani M, Kuchta K, Galloway T and Fundakowski C: Patterns of distant metastasis in head and neck cancer at presentation: Implications for initial evaluation. Oral Oncol 88: 131-136, 2019.

33. Kuperman DI, Auethavekiat V, Adkins DR, Nussenbaum B, Collins S, Boonchalermvichian C, Trinkaus K, Chen L and Morgensztern D: Squamous cell cancer of the head and neck with distant metastasis at presentation. Head Neck 33: 714-718, 2011.

34. Senft A, Hoekstra OS, Witte BI, Leemans CR and de Bree R: Screening for distant metastases in head and neck cancer patients using FDG-PET and chest CT: Validation of an algorithm. Eur Arch Otorhinolaryngol 273: 2643-2650, 2016.

This work is licensed under a Creative Commons Attribution-NonCommercial-NoDerivatives 4.0 International (CC BY-NC-ND 4.0) License. 